\title{
Genetic and Molecular Studies on Om, a Locus Controlling Mouse Preimplantation Development
}

\author{
M. Cohen-Tannoudj ${ }^{1}$, P. Balducci ${ }^{1}$, C. Kress', V. Richoux-Duranthon ${ }^{2}$, \\ J.P. Renard ${ }^{2}$, C. Babinet ${ }^{2}$ \\ 'Unité de Biologie du Développement, Institut Pasteur, Paris; 'Biologie du Développe- \\ ment, INRA Jouy en Josas, France
}

\section{INTRODUCTION}

Several lines of evidence have accumulated in recent years indicating that nuclear cytoplasmic interactions play an important role in the formation and fate of the developing mouse embryo. Early nuclear transplantation experiments indicated that the ability of nuclei to direct cleavage after transfer into enucleated zygotes falls abruptly with nuclei from more advanced preimplantation stages [1]. Transcriptional activation of the nuclei, which occurs during the second cell cycle probably precludes the reprogramming of nuclei from later cleavage stages [2]. Thus, when an 8-cell nucleus is transferred to an enucleated zygote, such a reconstituted zygote is blocked at the 2-cell stage. However, when identical 8-cell nuclei were transferred into both blastomeres of enucleated 2-cell embryos, they were able to support development to the blastocyst stage and even gave rise to live offspring [2-4]. This indicated the importance of the cytoplasmic environment for the ability of the incoming nucleus to support development. It should be noted that in these experiments, the nuclear cytoplasmic ratio was also an important factor in determining the development of the reconstituted embryos [2]. Similar observations were also made when monitoring the development of haploid embryos [5]. In another study, Latham and Solter [6] examined the ability of androgenones, obtained by replacing the female pronucleus of a zygote by the male pronucleus, to develop to the blastocyst stage. Androgenones generated from $\mathrm{C} 57 \mathrm{Bl} / 6$ eggs were found to be much more competent to give rise to blastocysts than were DBA/2 androgenones. However, when androgenones were constructed from (DBA/ $2 \times \mathrm{C} 57 \mathrm{~B} 1 / 6) \mathrm{F}_{1}$ zygotes (genetic constitution of the embryos will hereafter be indicated with the female parent coming first followed by the male parent), by replacing the $\mathrm{DBA} / 2$ female pronucleus with a $\mathrm{C} 57 \mathrm{Bl} / 6$ pronucleus, they also developed poorly. This was not simply due to the lack of some component in DBA/2 cytoplasm, since the impaired development was also observed when C57B 1/6 male pronuclei from pairs of $(\mathrm{DBA} / 2 \times \mathrm{C} 57 \mathrm{~B} 1 / 6) \mathrm{F}_{\text {, }}$ were transferred to an enucleated 
C57B1/6 egg. Rather, these results indicated that the developmental failure was the result of a stable epigenetic modification of the paternal C $57 \mathrm{~B} 1 / 6$ genome by the DBA/2 cytoplasm. More recently, Reik et al. [7] showed that changing the nucleocytoplasmic composition of a zygote could have an effect on the adult mouse phenotype. By exchanging maternal pronuclei between DBA/2 and C57B1/6 zygotes, they produced interstrain nucleocytoplasmic hybrids in which the maternal genome and the egg cytoplasm were of opposite genetic backgrounds (DBA/2 or C57B1/6). Control zygotes were produced in which the female pronucleus was removed from $(\mathrm{C} 57 \mathrm{Bl} / 6 \times \mathrm{DBA} / 2) \mathrm{F}_{1}$ eggs and replaced with a C57B1/6 pronucleus coming from another $(\mathrm{C} 57 \mathrm{~B} 1 / 6 \times \mathrm{DBA} / 2) \mathrm{F}_{\mathrm{i}}$ egg. Mice obtained from nucleocytoplasmic hybrids and control zygotes were compared, using 2D gel electrophoresis of liver proteins, and it was found that whereas the latter expressed the four major urinary proteins (MUPs), most of the former (25 out of 26) expressed very little of the MUPs. Thus, an adult phenotype, the expression of MUPs in adult liver, could be affected by extragenetic programming in the early embryo. In this paper, we will review experiments performed in our laboratory over several years, which also point to the importance of the interactions between parental genomes and egg cytoplasm for the development of the mouse zygote. These studies take advantage of the particular genetic properties of the DDK inbred mouse strain.

\section{The unusual properties of the DDK mouse inbred strain}

The genetic properties of the DDK inbred strain of mice were first described by Wakasugi and his colleagues [8]. When DDK female mice are crossed to males of other inbred strains, they generally exhibit a low fertility, whereas the reciprocal crosses (non-DDK females $\times$ DDK males) or intrastrain crosses are normally fertile (Fig. 1a). The degree of lethality of $(\mathrm{DDK} \times$ non-DDK $) \mathrm{F}_{\text {| }}$ embryos, referred to hereafter as the DDK syndrome, depends on the strain of the non-DDK male. It was subsequently shown that the low fertility was due to death of the hybrid embryos around the morula-blastocyst stage [9]. Impairment of gap junctional communication in $(D D K \times C 3 H) F_{1}$ embryos (a lethal combination) was shown more recently and could account for the lethality observed [10, 11]. To explain the DDK syndrome, and on the basis of various crosses between DDK and non-DDK strains, Wakasugi [12] proposed that a gene, $O m$, produces a substance $\mathrm{O}$ in the oocyte cytoplasm and that another closely linked gene encodes a product $S$ in the sperm. The alleles $\mathrm{O}$ and $\mathrm{S}$ occur in the majority of strains, whereas DDK mice have the alleles $o$ and $s$. When $o$ and $S$ are present together, their interaction is lethal to the embryo. The other combinations are normal.

\section{Developmental potential of zygotes with various nucleocytoplasmic compositions}

Wakasugi's genetic model to account for the lethality of (DDK $\times$ non-DDK) hybrid embryos postulated an incompatibility between a cytoplasmic product made by a DDK gene and a gene, or gene product, carried by the alien male sperm. To obtain more insight into the respective roles of the maternal and paternal genomes and the egg-cyto- 

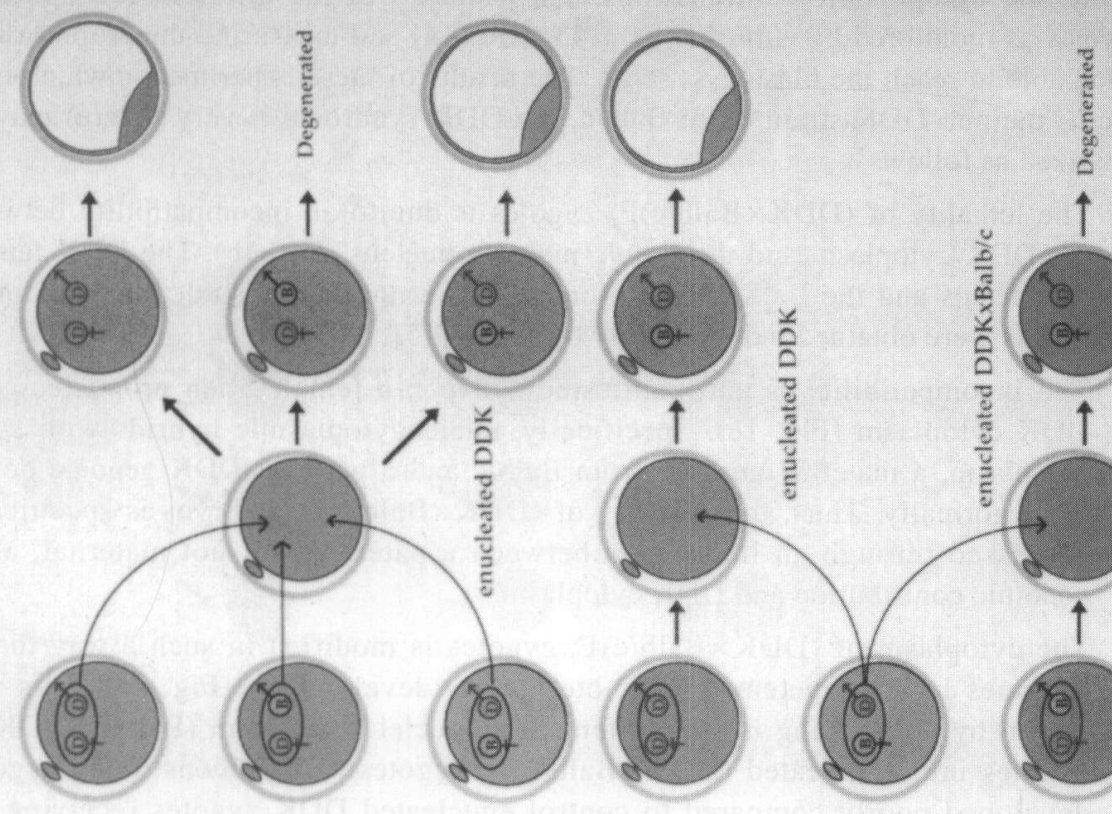

כ
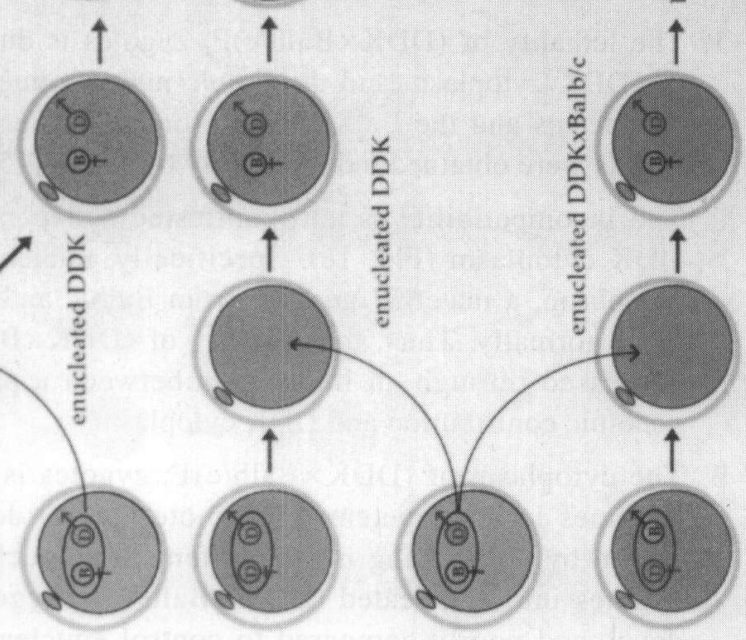

5
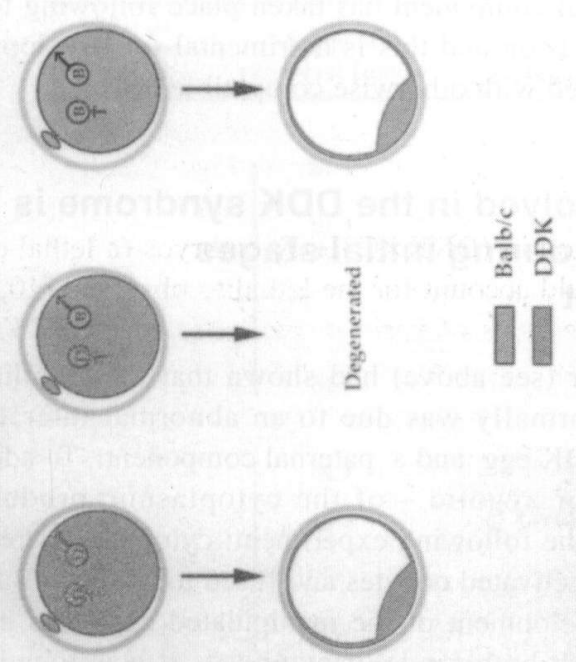

อ

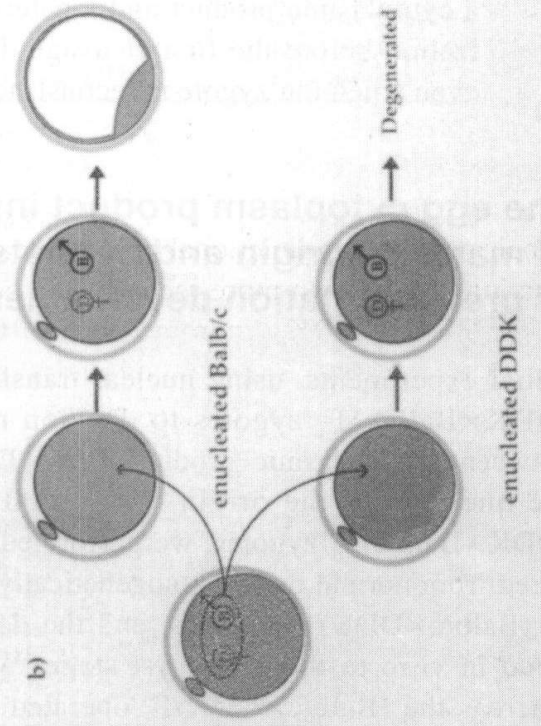

Fig. 1 - Developmental potential of embryos corresponding to different combinations of pronuclei and cytoplasm of DDK (D) and Balb/c (B) eggs. a) Embryos resulting from mating. b), c) and d) Embryos resulting from pronuclear transplations. 
plasm in the DDK syndrome, we used nuclear transfer [13] to generate eggs with various genomic and cytoplasmic combinations. The viability of the different reconstituted embryos was monitored by culturing them in vitro [14] and measuring the proportion of morulae able to reach the blastocyst stage. The results of these experiments, which used $\mathrm{Balb} / \mathrm{c}$ as the non-DDK strain (with Balb/c, the DDK syndrome is very severe) may be summarized as follows:

1. The lethality of $(\mathrm{DDK} \times \mathrm{Balb} / \mathrm{c}) \mathrm{F}_{1}$ zygotes is due to an incompatibility between the DDK cytoplasm and the Balb/c male pronucleus (Fig. Ib). The DDK female pronucleus and the Balb/c male pronucleus are not incompatible per se. Similar results were obtained independently by Mann [15].

2. The incompatibility is not manifested between a female alien pronucleus and DDK cytoplasm (Fig. 1c). Specifically, nucleocytoplasmic hybrids with DDK cytoplasm, a maternal genome from Balb/c and a paternal DDK genome developed normally. Thus, the lethality of $(\mathrm{DDK} \times \mathrm{Balb} / \mathrm{c}) \mathrm{F}_{1}$ embryos is specifically expressed through an interaction between a paternal, but not maternal, alien genomic contribution and DDK cytoplasm.

3. The cytoplasm of $(\mathrm{DDK} \times \mathrm{Balb} / \mathrm{c}) \mathrm{F}_{1}$ zygotes is modified in such a way that it becomes less competent to promote normal development (Fig. 1d). This was shown by transferring male and female pronuclei taken from $(\mathrm{Balb} / \mathrm{c} \times \mathrm{DDK}) \mathrm{F}_{\text {, }}$ zygotes into enucleated (DDK $\times \mathrm{Balb} / \mathrm{c}) \mathrm{F}_{1}$ zygotes: such reconstituted zygotes developed poorly compared to control enucleated DDK zygotes receiving the same combination of pronuclei. This suggests that an aberrant interaction between a cytoplasmic product and a paternal component has taken place following fertilization before the first cleavage division and this is detrimental for development even when the zygote is reconstructed with otherwise compatible pronuclei.

\section{The egg cytoplasm product involved in the DDK syndrome is of maternal origin and persists during initial stages of preimplantation development}

Initial experiments, using nuclear transfer (see above) had shown that the inability of $(\mathrm{DDK} \times \mathrm{Balb} / \mathrm{c}) \mathrm{F}_{1}$ zygotes to develop normally was due to an abnormal interaction between a cytoplasmic product of the DDK egg and a paternal component. To address the question of the origin - maternal or zygotic - of the cytoplasmic product in $(D D K \times B a l b / c) F_{1}$ zygotes, we performed the following experiment: cytoplasts were prepared from normal or parthenogenetically activated oocytes and fused to (Balb/c $\times \mathrm{Balb} / \mathrm{c}$ ) or $(\mathrm{Balb} / \mathrm{c} \times \mathrm{DDK}) \mathrm{F}_{1}$ zygotes, and the development of the manipulated eggs was monitored in vitro to the blastocyst stage. With both kinds of cytoplasts it was found that whereas the $(\mathrm{Balb} / \mathrm{c} \times \mathrm{DDK}) \mathrm{F}_{1}$ operated embryos developed normally to the blastocyst stage, the Balb/c $\times$ Balb/c eggs were compromised (Fig. 2, Table 1). The experiments demonstrated that one of the components responsible for the DDK syndrome is a maternal factor and further confirms that its action depends on the paternal genotype of the fused embryo. We then examined if the maternal factor could be active at later cleavage stages; experiments were performed reconstituting embryos from individual blastomeres previ- 
a)

Dissociation of blastomeres
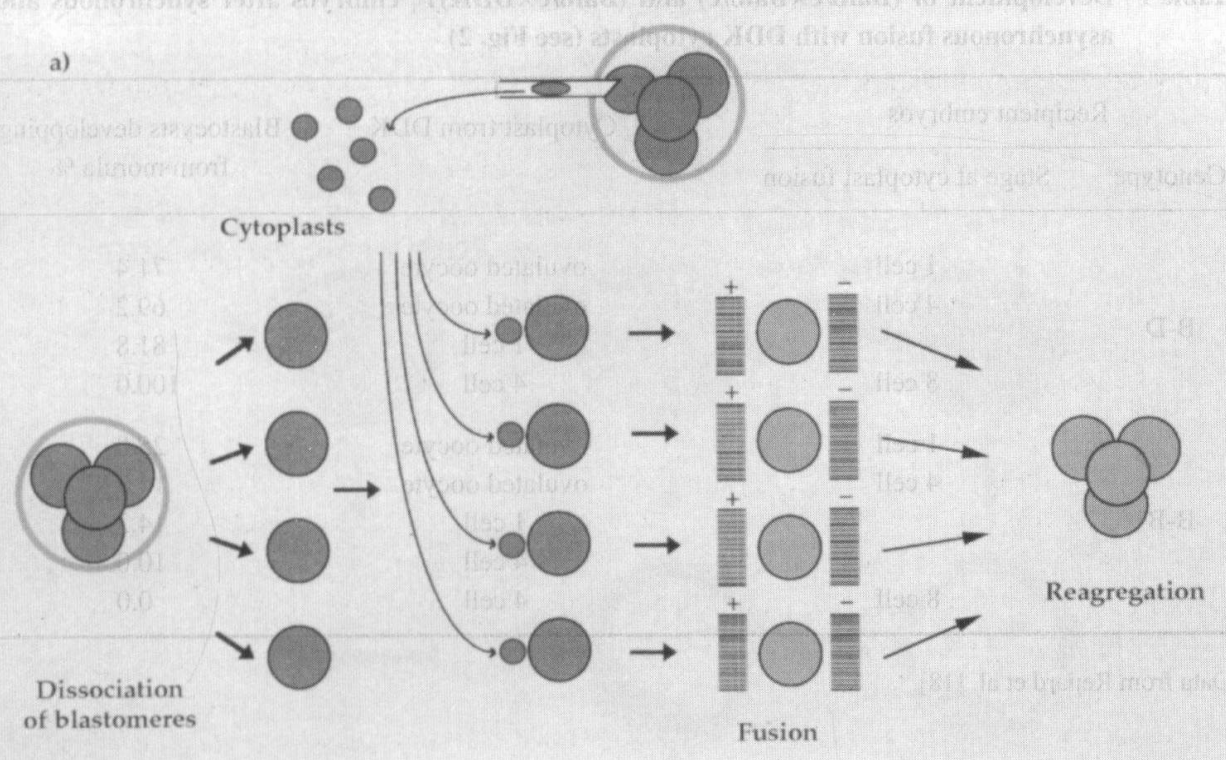

b)

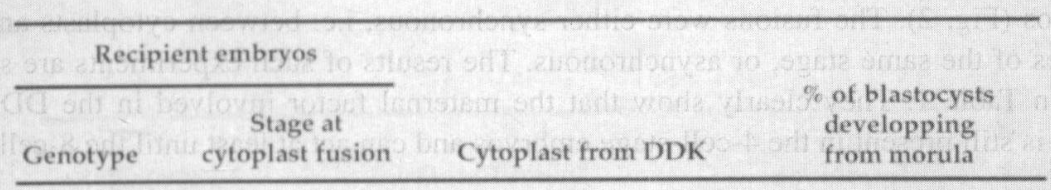

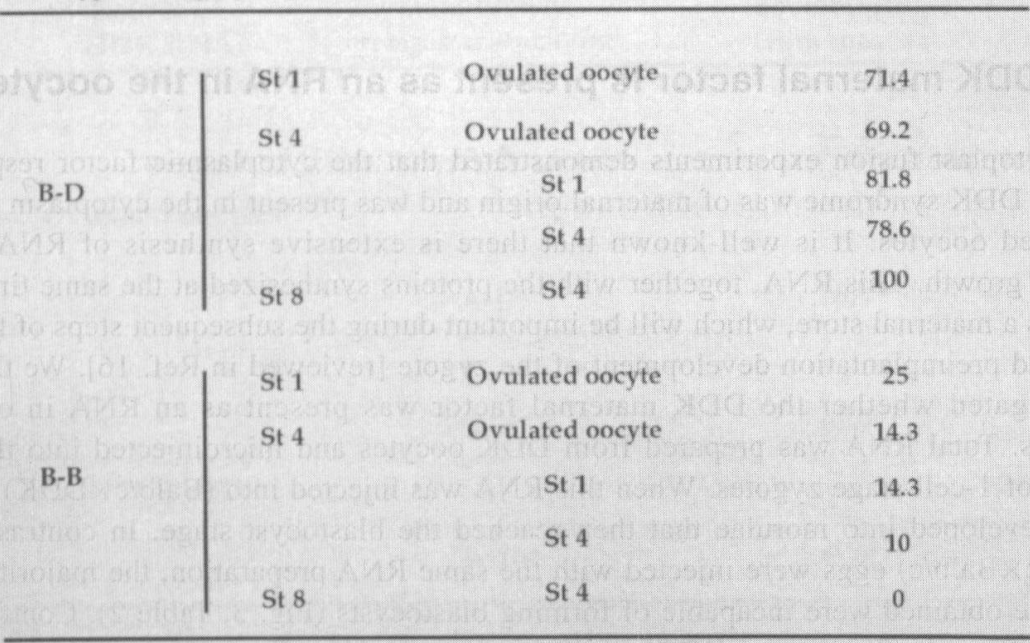

Fig. 2 - Development of $(B a l b / c \times B a l b / c)$ and $(B a l b / c \times D D K) F_{1}$ embryos after synchronous and asynchronous fusion with DDK cytoplasts. Schematic representation of the experimental proceedure of synchronous DDK cytoplast fusion with Balb/c 4-cell stage. 
Table 1 - Development of $(B a l b / c \times B a l b / c)$ and $(B a l b / c \times D D K) F_{1}$ embryos after synchronous and asynchronous fusion with DDK cytoplasts (see Fig. 2)

\begin{tabular}{|c|c|c|c|}
\hline \multicolumn{2}{|c|}{ Recipient embryos } & \multirow[t]{2}{*}{ Cytoplast from DDK } & \multirow{2}{*}{$\begin{array}{c}\text { Blastocysts developping } \\
\text { from morula } \%\end{array}$} \\
\hline Genotype & Stage at cytoplast fusion & & \\
\hline \multirow{4}{*}{ B-D } & 1 cell & ovulated oocyte & 71.4 \\
\hline & 4 cell & ovulated oocyte & 69.2 \\
\hline & & 1 cell & 81.8 \\
\hline & 8 cell & 4 cell & 100.0 \\
\hline \multirow{5}{*}{ B-B } & 1 cell & ovulated oocyte & 25.0 \\
\hline & 4 cell & ovulated oocyte & 14.3 \\
\hline & & 1 cell & 14.3 \\
\hline & & 4 cell & 10.0 \\
\hline & 8 cell & 4 cell & 0.0 \\
\hline
\end{tabular}

Data from Renard et al. [18].

ously fused with cytoplasts: as with oocytes, DDK cytoplasts from different cleaving stages were fused with blastomeres of either $(\mathrm{Balb} / \mathrm{c} \times \mathrm{DDK}) \mathrm{F}_{1}$ or $(\mathrm{Balb} / \mathrm{c} \times \mathrm{Balb} / \mathrm{c})$ embryos (Fig. 2). The fusions were either synchronous, i.e. between cytoplasts and blastomeres of the same stage, or asynchronous. The results of such experiments are summarized in Table 1. They clearly show that the maternal factor involved in the DDK syndrome is still present in the 4-cell-stage embryos and can act at least until the 8-cell stage.

\section{The DDK maternal factor Is present as an RNA in the oocyte}

The cytoplast fusion experiments demonstrated that the cytoplasmic factor responsible for the DDK syndrome was of maternal origin and was present in the cytoplasm of DDK ovulated oocytes. It is well-known that there is extensive synthesis of RNA during oocyte growth. This RNA, together with the proteins synthesized at the same time, constitutes a maternal store, which will be important during the subsequent steps of fertilization and preimplantation development of the zygote [reviewed in Ref. 16]. We therefore investigated whether the DDK maternal factor was present as an RNA in ovulated oocytes. Total RNA was prepared from DDK oocytes and microinjected into the cytoplasm of 1-cell-stage zygotes. When this RNA was injected into $(\mathrm{Balb} / \mathrm{c} \times \mathrm{DDK}) \mathrm{F}_{\text {, }}$ eggs, they developed into morulae that then reached the blastocyst stage. In contrast, when $(\mathrm{Balb} / \mathrm{c} \times \mathrm{Balb} / \mathrm{c})$ eggs were injected with the same RNA preparation, the majority of the morulae obtained were incapable of forming blastocysts (Fig. 3, Table 2). Control RNA from different cell types of DDK origin (embryonic fibroblasts, adult testis or ovaries) were without effect on the development of morulae obtained from $(\mathrm{Balb} / \mathrm{c} \times \mathrm{Balb} / \mathrm{c})$ injected zygotes. Taken together, these experiments demonstrate that the maternal factor involved in the DDK syndrome is present as an RNA in the ovulated oocyte and has therefore presumably been synthesized during the growth phase of the oocyte. 
a)

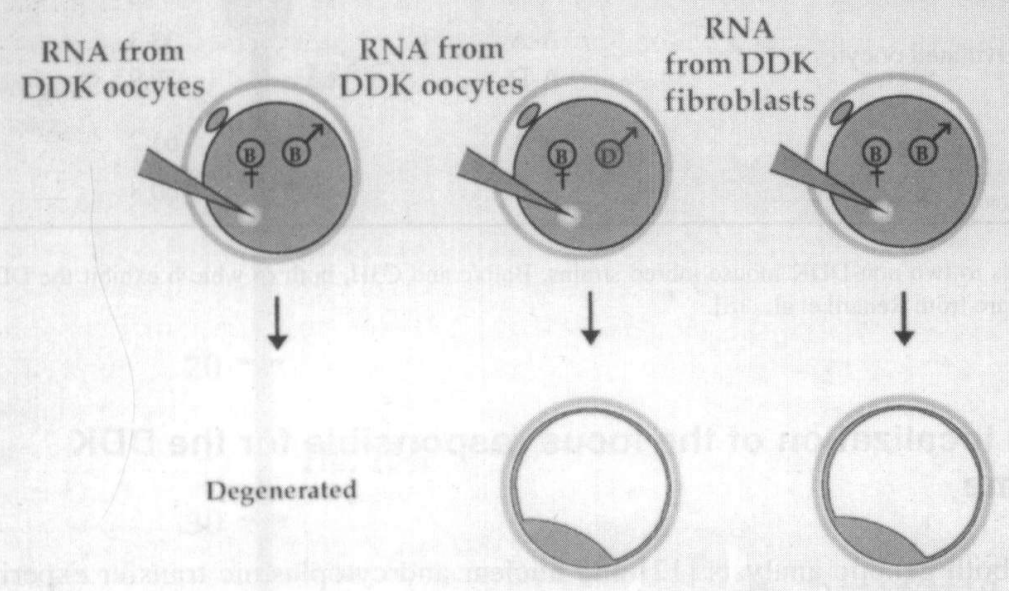

b)

\begin{tabular}{|c|c|c|}
\hline $\begin{array}{c}\text { Source of } \\
\text { DDK RNA }\end{array}$ & $\begin{array}{l}\text { Genotype of } \\
\text { recipient embryos }\end{array}$ & $\begin{array}{l}\text { \% of blastocysts } \\
\text { developping } \\
\text { from morula }\end{array}$ \\
\hline
\end{tabular}

$$
\text { A-A }
$$

Ovulated oocytes

Fibroblasts

A-D 60.8

Fig. 3 - DDK (d) RNA injection into (alien $\times$ alien) and (alien $\times$ DDK) $F_{1}$ eggs. Schematic representation of the experimental procedure using Balb/c $(b)$ as the alien strain. 
Table 2 - DDK RNA injection into (alien $\times$ alien) and (alien $\times$ DDK) $F_{1}$ eggs

\begin{tabular}{ccc}
\hline $\begin{array}{c}\text { Source of } \\
\text { DDK RNA }\end{array}$ & $\begin{array}{c}\text { Genotype of } \\
\text { recipient embryos }\end{array}$ & $\begin{array}{c}\text { Blastocysts developping } \\
\text { from morula \% }\end{array}$ \\
\hline \multirow{2}{*}{ Ovulated oocytes } & A-A & 33.3 \\
& A-D & 76.9 \\
Fibroblasts & A-A & 65.2 \\
& A-D & 60.8 \\
\hline
\end{tabular}

A corresponds to two non-DDK mouse inbred strains, Balb/c and $\mathrm{C} 3 \mathrm{H}$, both of whic h exhibit the DDK syndrome. Data are from Renard et al. [18].

\section{Genetic localization of the locus responsible for the DDK syndrome}

Although both genetic analysis [12] and nuclear and cytoplasmic transfer experiments [see above and Ref. 17, 18] have clearly shown that the lethal condition of (DDK $\times$ non-DDK) hybrid embryos was due to incompatibility between a cytoplasmic product of maternal origin that is present as an RNA in DDK oocyte cytoplasm [18] and some alien paternal component, nothing is known about the molecular mechanisms underlying this incompatibility. As a first step towards identifying the gene(s) responsible for the observed lethality, we have set out to determine the genetic localization of the locus (or loci) involved [19]. In a first series of experiments, a backcross was set up, using Balb/c as the alien strain. Balb/c females were crossed with DDK males and the $F_{1}$ males resulting from this cross were then backcrossed to Balb/c females, giving rise to backcross 1 individuals $\left(\mathrm{BC}_{1}\right) . \mathrm{BC}$, males were then analysed in two assays to determine their phenotype with respect to the DDK syndrome. In an in vivo assay they were crossed with either DDK or Balb/c females and the litter sizes of both types of crosses were recorded. In parallel, an in vitro assay was performed, in which $(\mathrm{DDK} \times \mathrm{BC} 1)$ 3-day-old embryos were collected and monitored for their development in vitro to the blastocyst stage; controls for the in vitro assay were (DDK $\times$ DDK), $(\mathrm{DDK} \times \mathrm{Balb} / \mathrm{c})$ and $\mathrm{DDK} \times(\mathrm{Balb} / \mathrm{c} \times \mathrm{DDK}) \mathrm{F}_{1}$ embryos. Both in vivo and in vitro assays gave the same kind of results: when crossed with $\mathrm{DDK}$ females, $\mathrm{BC}_{1}$ males were distributed in two classes, one with an $F_{1}$ phenotype (exhibiting an intermediate developmental potential) and the other with a Balb/c phenotype (very few embryos developing). This showed that a single locus is responsible for the DDK syndrome, as postulated by Wakasugi [12]. The analysis of the segregation of various genetic markers in the backcross progeny allowed the localization of this locus, Om, close to Scyal and Scya2 (formerly called Tca and Sigje) on chromosome 11 (Fig. 4) [19]. Using a different genetic approach, Sapienza et al. [20] found a similar chromosomal localization for $O m$. A high-resolution map of the region has since established that $O m$ lies within a 2cM region, bordered by the markers DllMit33 and DllMit36 (Fig. 4) [Baldacci et al., in prep.]. 


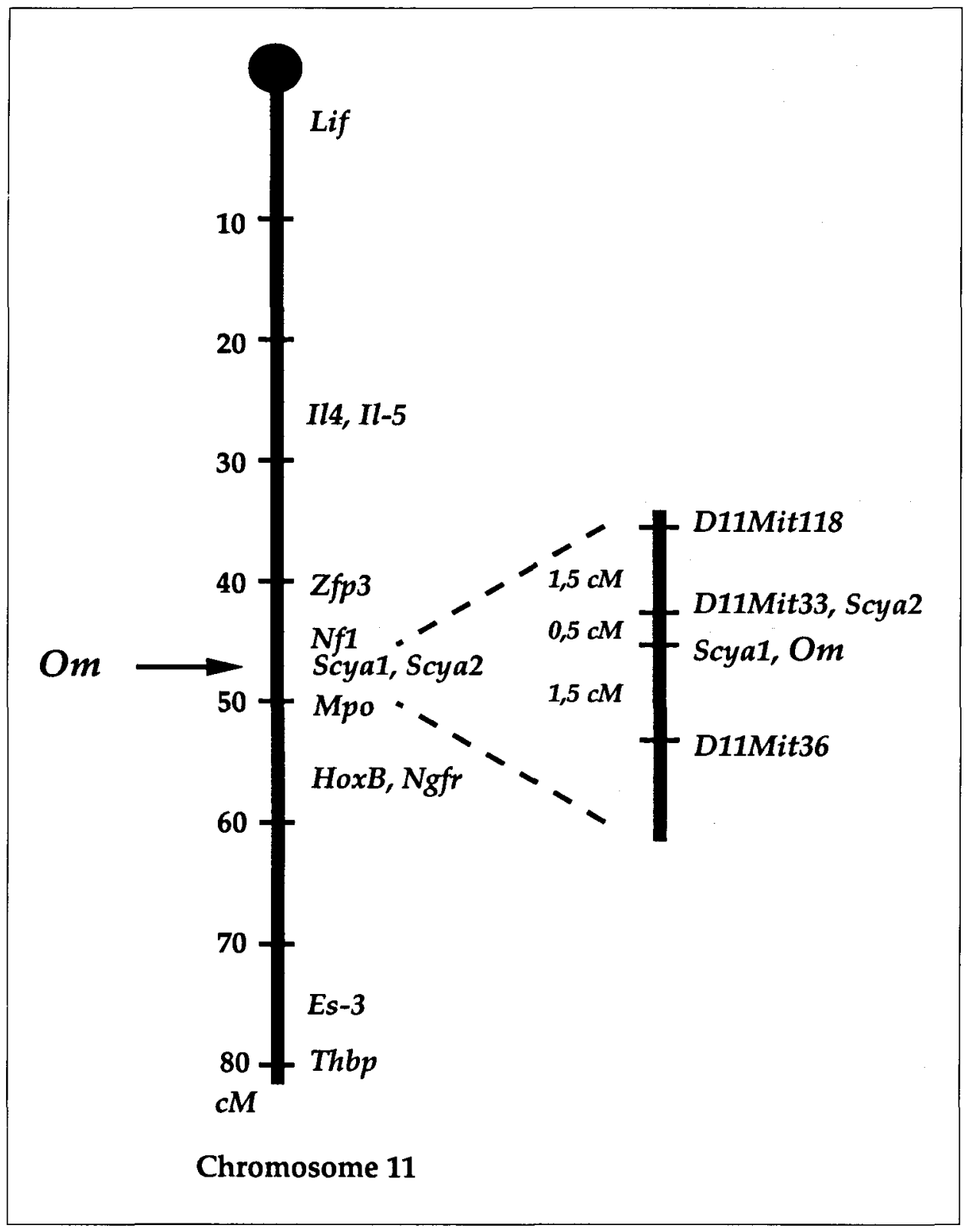

Fig. 4 - Genetic mapping of $O m$ locus. 


\section{Concluding remarks}

Following the work of Wakasugi [12], who first described the unusual genetic properties of the mouse strain DDK, we have been able, using different experimental approaches, to demonstrate that the DDK syndrome is due to an interaction between a product present in DDK egg cytoplasm and the alien male genome or male genome products. We also showed that the DDK cytoplasmic factor was of maternal origin. Furthermore, nuclear transfer experiments indicated that the lethal interaction was manifested when the alien genome was of paternal but not maternal origin. Hence, the lethality of (DDK $\times$ alien) $F_{1}$ embryos can be interpreted as the result of both a maternal and a paternal effect. The fact that DDK oocyte RNA could induce the DDK syndrome when injected into a zygote endowed with an alien paternal genome is reminiscent of the maternal effects observed, for example in Drosophila melanogaster or Caenorhabditis elegans and originating from the impairment of a gene product made during oogenesis [21]. To our knowledge, these observations constitute the first direct evidence in mammals of maternal control at work during embryonic development. They also rule out a recently proposed model [20], which relied on aberrant imprinting of the $\mathrm{Om}$ locus in the DDK line. Indeed, imprinting deals with postzygotic expression of one or the other allele of a gene depending on its parental origin and, therefore, the imprinting model is not consistent with our finding of a maternal product in the oocytes involved in the DDK syndrome. At the present time, it is difficult to decide whether the paternal effect we have disclosed is due to a product carried by the alien sperm or to the activity of a paternal gene soon after fertilization and during the pronuclear stage. The latter hypothesis is problematic, as considerable evidence indicates that zygotic gene expression does not begin until after the first cleavage [reviewed in Ref. 22].

The lethality of (DDK $\times$ alien) $F_{1}$ embryos as well as other features of the DDK syndrome described here are unique to DDK, as no other case of hybrid failure has been described in crosses between laboratory mice. Hence, DDK can be viewed as a strain carrying a mutation that has made it possible to reveal a crucial type of interaction between maternal and paternal components of the fertilized egg. When this interaction is

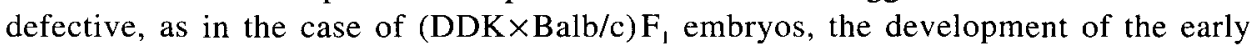
embryo is compromised. Although we favour this hypothesis, we cannot formally exclude an alternative one in which the mutation causes an ectopic expression of some gene(s) normally silent during oogenesis. Earlier genetic studies by Wakasugi [12] indicated that a single locus called $O m$ was responsible for the DDK syndrome. This was recently confirmed in our laboratory and by another group which, using different genetic approaches, could map this locus to the distal part of chromosome 11. Importantly, we could also show that both parental effects depended on the genetic constitution of the $O m$ locus: indeed, when examining the status of animals from recombinant inbred strains following crosses between DDK and Balb/c, we found that both males and females of a given line were either of the DDK or the Balb/c type.

While it is now clear that a single locus, the position of which on the genetic map has been established, determines a quite complex phenotype including early death of interstrain embryos and parental effects, several issues pertaining to the genetic properties of DDK remain unsolved. For example, it is known that the degree of lethality depends on the alien strain used $[8,14]$. This could indicate that either there are different alien $\mathrm{Om}$ 
alleles or that some other genes may modulate the extent of the syndrome. Secondly, it has been shown that embryos born from (DDK $\times$ alien) $F_{1}$ females backcrossed to alien males exhibited intermediate lethality [20, 12], about half of the embryos dying. In view of our results demonstrating the expression of the $\mathrm{Om}^{\mathrm{d}}$ product in DDK oocytes, both $\mathrm{Om}^{\mathrm{d}}$ and alien Om products should be present in $\mathrm{F}_{1}$ oocytes and it is not clear how they would compete for the putative male product to give the observed result, i.e. the death of about half of the embryos. To solve this issue, one could hypothesize that in the female germ-line, $O m$ expression is subject to allelic exclusion which would result in the presence in the ovulated hybrid oocyte of either the $\mathrm{Om}^{\mathrm{d}}$ or the alien $\mathrm{Om}$ product, regardless of the $\mathrm{Om}$ allele ultimately transmitted to the progeny; in this context, it is interesting to note that monoallelic expression has recently been disclosed for olfactory receptor genes [23], thus adding a fourth case of functional hemizygosity to the three already known, namely $\mathrm{X}$-chromosome inactivation, parental imprinting and allelic exclusion of immunoglobulin and $\mathrm{T}$ cell receptor genes. Consistent with this hypothesis, we found that roughly half the animals born to $(\mathrm{Balb} / \mathrm{c} \times \mathrm{DDK}) \mathrm{F}_{1}$ females crossed to Balb/c males inherited an $\mathrm{Om}^{\mathrm{d}}$ allele. All the available evidence, either genetic or embryological, indicates an interaction between a DDK maternal product and an alien male component. That the latter is not merely a genomic component but rather a gene product is suggested by early nuclear transplantation experiments; indeed Renard and Babinet [14] showed that the cytoplasm of an enucleated $(\mathrm{DDK} \times \mathrm{Balb} / \mathrm{c}) \mathrm{F}_{1}$ zygote was less competent than the cytoplasm of a (DDK $\times$ DDK) zygote in its ability to interact with male and female pronuclei to promote normal development. Thus, this "toxic" effect was most probably due to an alien male genomic product since it could manifest itself in the absence of the alien male genome. At the present time, it is not possible to decide whether the maternal and paternal gene products are expressed from a single gene or from two genes. In the former case, the gene would necessarily function differentially in the female and male germ-lines. Positional cloning of the $O m$ gene(s) currently in progress in our laboratory should help to address these different issues and particularly the molecular mechanisms implicated in the embryonic lethal syndrome.

\section{REFERENCES}

1. McGrath J, Solter D: Inability of mouse blastomere nuclei transferred to enucleated zygotes to support development in vitro. Science 1984; 226: 1317-1319.

2. Howlett SK, Barton SC, Surani MA: Nuclear cytoplasmic interactions following nuclear transplantation in mouse embryos. Development 1987; 101: 915-923.

3. Tsunoda Y, Yasui T, Shioda Y, Nakamura K, Uchida T, Sugie T: Full term development of mouse blastomere nuclei transplanted to enucleated two-cell embryos. J Exp Zool 1987; 242: 147-151.

4. Barnes FL, Robl JM, First NL: Transplantation in mouse embryos: Assessment of nuclear function. Biol Reprod 1987; 36: 1267-1274.

5. McGrath J, Solter D: Nucleocytoplasmic interactions in the mouse embryo. J Embryol Exp Morphol 1986; 97 (suppl): 277-289.

6. Latham KE, Solter D: Effect of egg composition on the developmental capacity of androgenetic mouse embryos. Development 1991; 113: 561-568.

7. Reik W, Römer I, Barton SC, Surani MA, Howlett SK, Klose J: Adult phenotype in the mouse can be affected by epigenetic events in the early embryo. Development 1993; 119: 933-942. 


\section{M. Cohen-Tannoudji et al.}

8. Wakasugi N, Tomita T, Kondo K: Differences of fertility in reciprocal crosses between inbred strains of mice DDK, KK and NC. J Reprod Fertil 1967; 13: 41-50.

9. Wakasugi N: Studies on fertility of DDK and C57B1/6J strains and experimental transplantation of the ovary. J Reprod Fertil 1972; 33: 283-291.

10. Buehr M, Lee S, McLaren A, Warner A: Reduced gap junctional communications is associated with the lethal condition characteristic of DDK mouse eggs fertilized by foreign sperm. Development 1987; 101: 449-459.

11. Leclerc C, Becker D, Buehr M, Warner A: Low intracellular pH is involved in the early embryonic death of DDK mouse eggs fertilized by alien sperm. Dev Dyn 1994; 200: 257-267.

12. Wakasugi N: A genetically determined incompatibility system between spermatozoa and eggs leading to embryonical death in mice. J Reprod Fertil 1974; 41: 85-94.

13. McGrath J, Solter D: Nuclear transplantation in the mouse embryo by microsurgery and cell fusion. Science 1983; 220: 1300-1302.

14. Renard JP, Babinet C: Identification of a paternal developmental effect on the cytoplasm of one-cell-stage mouse embryos. Proc Natl Acad Sci USA 1986; 83: 6883-6886.

15. Mann JR: DDK egg-foreign sperm incompatibility in mice is not between the pronuclei. J Reprod Fertil 1986; 76: 779-781.

16. Wassarman PM, Kinloch RA: Gene expression during oogenesis in mice. Mutat Res 1992; 296: 3-15.

17. Babinet C, Richoux V, Guenet JL, Renard JP: The DDK inbred strain as a model for the study of interactions between parental genomes and egg cytoplasm in mouse preimplantation development. Development 1990; (suppl): 81-87.

18. Renard JP, Baldacci P, Richoux-Duranthon V, Pournin S, Babinet C: A maternal factor affecting mouse blastocyst formation. Development 1994; 120: 797-802.

19. Baldacci PA, Richoux V, Renard JP, Guénet JL, Babinet C: The locus Om, responsible for the DDK syndrome, maps close to Sigje on mouse chromosome 11. Mamm Genome 1992; 2: 100105.

20. Sapienza C, Paquette J, Pannunzio P, Albrechtson S, Morgan K: The polar-lethal ovum mutant gene maps to the distal portion of mouse chromosome 11. Genetics 1992; 132: 241-246.

21. Wilson GN: Mutational risks in females: Genomic imprinting and maternal molecules. Mutat Res 1992; 296: 157-165.

22. Schultz GA, Heyner S: Gene expression in pre-implantation mammalian embryos. Mutat Res 1992; 296: 17-31.

23. Chess A, Simon I, Cedar H, Axel R: Allelic inactivation regulates olfactory receptor gene expression. Cell 1994;78: 823-834.

Correspondent: Dr. Charles Babinet, Institut Pasteur, Unité de Biologie du Développement -25 , rue du Docteur Roux, 75724 Paris Cedex 15, France. 